Erratum

\title{
Erratum to "The Association between Preoperative Dry Eye Symptoms and Postoperative Discomfort in Patients Underwent Photorefractive Keratectomy"
}

\author{
Gilad Rabina $\mathbb{D}^{1},{ }^{1}$ Ingibjorg Iris Boguslavsky, ${ }^{2}$ Michael Mimouni $\mathbb{D}^{3}{ }^{3}$ \\ and Igor Kaiserman $\mathbb{C}^{2,4,5}$ \\ ${ }^{1}$ Department of Ophthalmology, Tel Aviv Sourasky Medical Center, The Sackler Faculty of Medicine, Tel Aviv University, \\ Tel Aviv, Israel \\ ${ }^{2}$ Department of Ophthalmology, Barzilai University Medical Center, Ashkelon, Israel \\ ${ }^{3}$ Department of Ophthalmology, Rambam Health Care Campus, The Bruche and Ruth Rappaport Faculty of Medicine, \\ Technion-Israel Institute of Technology, Haifa, Israel \\ ${ }^{4}$ Faculty of Health Science, Ben Gurion University, Be'er Sheva, Israel \\ ${ }^{5}$ Care Vision Laser Refractive Center, Tel Aviv, Israel \\ Correspondence should be addressed to Gilad Rabina; giladrabina@hotmail.com
}

Received 20 May 2019; Accepted 23 May 2019; Published 16 June 2019

Copyright (C) 2019 Gilad Rabina et al. This is an open access article distributed under the Creative Commons Attribution License, which permits unrestricted use, distribution, and reproduction in any medium, provided the original work is properly cited.

In the article titled "The Association between Preoperative Dry Eye Symptoms and Postoperative Discomfort in Patients Underwent Photorefractive Keratectomy" [1], Dr. Shmuel Levartovsky was incorrectly included as an author. The corrected authors' list and affiliations are shown above and updated in place.

\section{References}

[1] G. Rabina, I. I. Boguslavsky, M. Mimouni, and I. Kaiserman, "The association between preoperative dry eye symptoms and postoperative discomfort in patients underwent photorefractive keratectomy," Journal of Ophthalmology, vol. 2019, Article ID 7029858, 6 pages, 2019. 


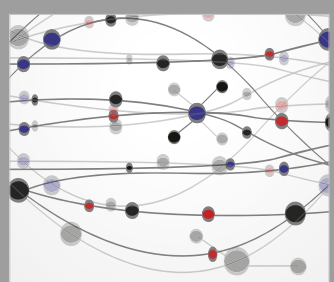

The Scientific World Journal
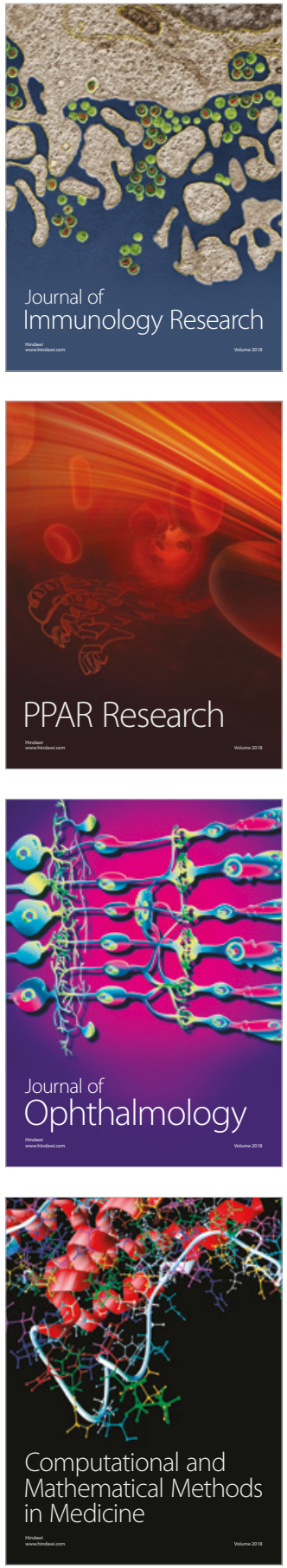

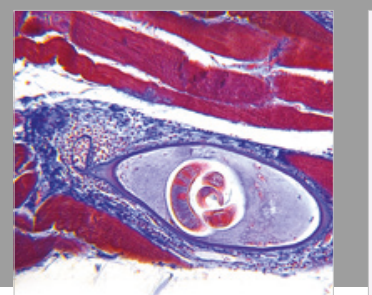

Gastroenterology Research and Practice

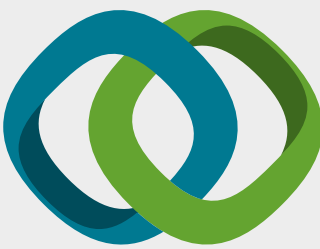

\section{Hindawi}

Submit your manuscripts at

www.hindawi.com
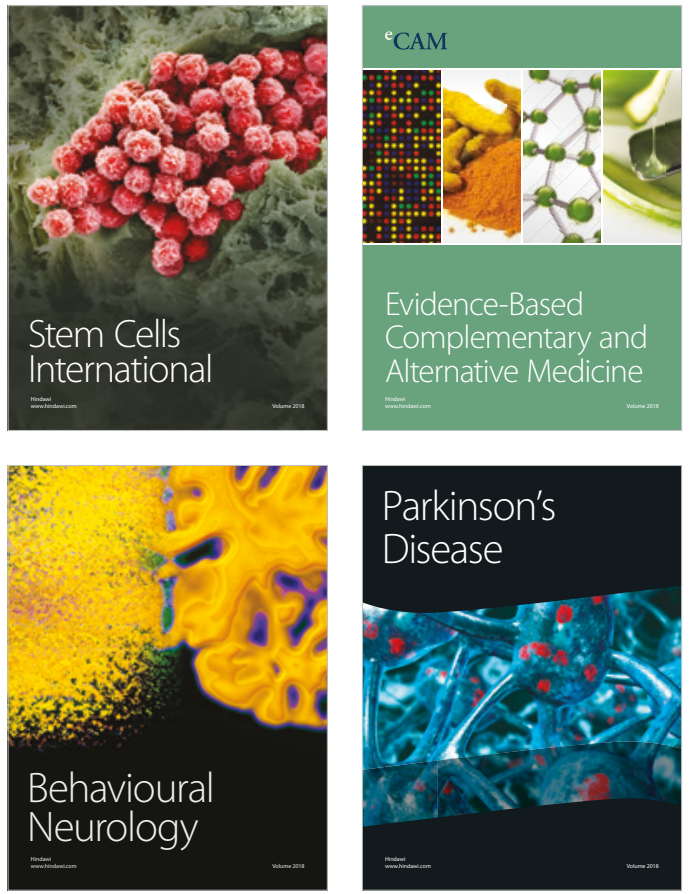

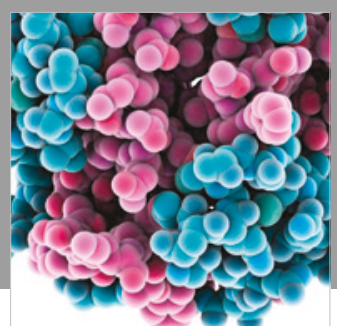

ournal of

Diabetes Research

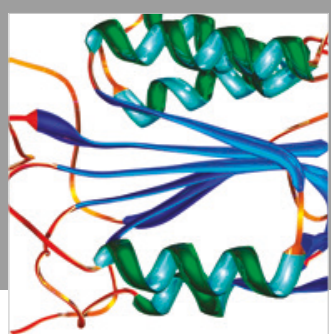

Disease Markers
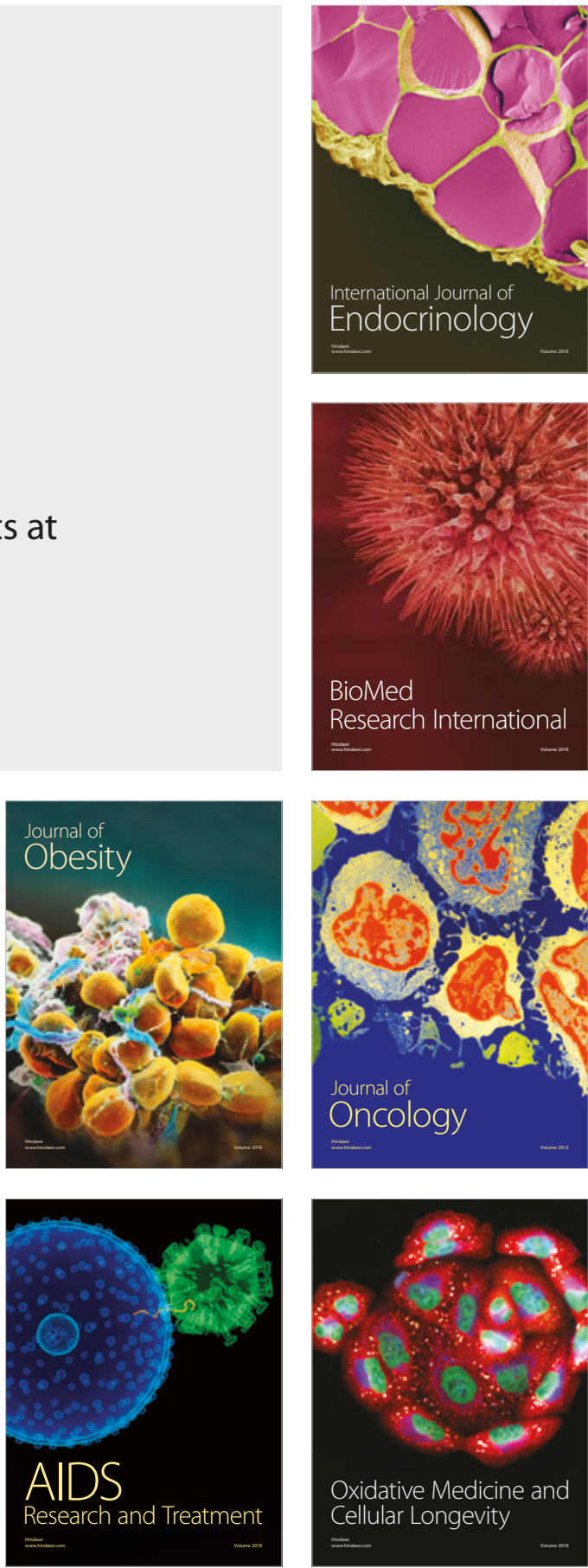